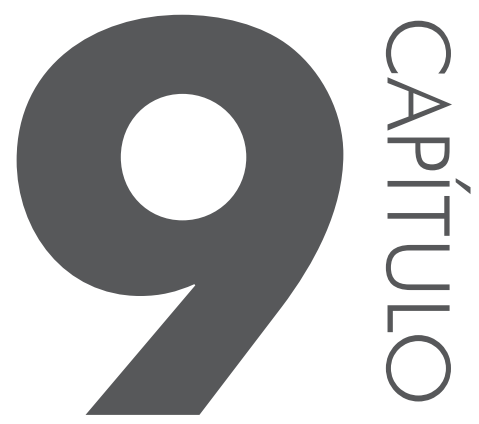

\title{
Políticas patrimoniais e projetos nacionalistas: línguas e brasilidade em tela
}

Cristine Gorski Severo

\subsection{INTRODUC̣ÃO}

As políticas de preservação dos bens culturais no Brasil desempenham um papel político na construção de um imaginário de nação e de nacionalismo, no embalo de outras políticas que buscam demarcar simbolicamente os limites do Estado Nacional (TRAJANO, 2012). Embora tais políticas visem um fortalecimento desse simbolismo nacional, elas também respondem às demandas das políticas internacionais de patrimonialização vinculadas à UNESCO. Tendo em vista essa dupla face - externa e interna - das políticas de patrimonialização, o presente capítulo pretende discutir o papel desempenhado pelas línguas nas práticas de patrimonialização a partir de uma perspectiva historiográfica e política. A discussão se enquadra na área de políticas linguísticas e dialoga com as iniciativas estatais contemporâneas de reconhecimento da diversidade linguística brasileira. Busca-se neste texto problematizar o interesse recente do Estado, a partir dos anos 2000, pela preservação da diversidade linguística à luz de um projeto governamental que, em grande medida, opera de forma verticalizada 
(top-down), estabelecendo, muitas vezes, diálogos frágeis ou quase inexistentes com as comunidades linguísticas envolvidas. $\mathrm{O}$ texto discute o conceito de língua das políticas de patrimonialização e as contradições que tais conceitos enfrentam ao lidar com as práticas linguísticas reais e concretas. Além disso, indaga-se a respeito do papel desempenhado pelos saberes especializados - a Linguística - na produção de políticas estatais.

O capítulo se estrutura da seguinte maneira: inicialmente discute-se o conceito de patrimonialização a partir de instâncias nacionais, com enfoque na criação do Instituto do Patrimônio Histórico e Artístico Nacional - IPHAN (Ministério da Cultura), pontuando o papel da patrimonialização na construção de um discurso nacional; em seguida, apresenta-se um panorama das iniciativas políticas patrimoniais, explícitas e implícitas, em torno da língua, em diálogo com as esferas internacionais; por fim, problematiza-se o conceito de língua dessas políticas patrimoniais em face das ideias de política e de cultura que veiculam.

\subsection{CONTEXTUALIZANDO A PATRIMONIALIZAC̣ÃO: ARTICULAC̣ÃO ENTRE INTELECTUAIS E POLÍTICOS}

A ideia de patrimônio, vinculado à esfera pública, emergiu no contexto dos Estados Nacionais europeus, criando um sentimento de coletividade em relação a uma dada herança artística e cultural, impedindo que os nobres e reis monopolizassem esses bens: "Assim, as heranças dos nobres eram apropriadas como heranças do povo de cada Estado-Nação, sendo relidas com novos sinais diacríticos" (ABREU, 2009, p. 35). No Brasil, os interesses pela preservação de bens considerados culturais remontam à chegada da família real no Rio de Janeiro, em 1808, embora preocupações desta natureza existissem já no século XVIII (BORGES, 1999). Exemplificando as iniciativas imperiais em torno das práticas de conservação dos bens culturais brasileiros, a primeira instituição dedicada a esse projeto foi a Escola Real de Ciências, Artes e Ofícios, criada pelo decreto de 12 de agosto de 1816, e que, posteriormente, se tornou o Museu Nacional de Belas Artes. Tal iniciativa foi motivada por artistas e intelectuais europeus e brasileiros, que estavam ocupados com a produção de registros sobre a realidade brasileira. Dentre alguns personagens que participaram dessa criação, estão Joaquim Lebreton, Jean-Baptiste Debret, Grandjean de Montigny e NicolasAntoine Taunay, artistas franceses cujos registros iconográficos ainda habitam os livros didáticos de história brasileira.

Após a Independência, entre 1870 e 1930, houve no Brasil uma fase intensa de construção de museus nacionais etnográficos que se voltavam à pesquisa, 
conservação, classificação e exibição de objetos materiais, especialmente da área de ciências naturais, seguindo os modelos epistemológicos evolucionistas (SCHWARCZ, 2008). Desse período é importante destacar o papel desempenhado pelos modernistas e a Semana da Arte Moderna de 1922 nas políticas de conservação do patrimônio cultural brasileiro, uma vez que esses intelectuais contribuíram fortemente para as políticas nacionalistas do Brasil.

A relação entre os intelectuais e a política foi intensificada no contexto do Estado Novo, o que se exemplifica pelo papel desempenhado pelo projeto cultural de Carlos Drummond de Andrade, Mário de Andrade, Oscar Niemeyer e Portinari no Ministério da Educação, sob regência de Gustavo de Capanema; outro exemplo de articulação entre políticos e intelectuais foi a incorporação de Getúlio Vargas à Academia Brasileira de Letras em 1943, com um discurso que defendia a aproximação entre pensamento teórico e ação política (VELLOSO, 1987).

O Serviço do Patrimônio Histórico e Artístico Nacional - SPHAN foi idealizado por Mário de Andrade em 1936, quando era diretor do Departamento de Cultura de São Paulo, no contexto do Estado Novo (1937-1945) e como fruto de uma política cultural nacionalista (FAUSTO, 2002). O SPHAN foi efetivamente criado em 1937, motivando uma série de iniciativas de tombamento de bens materiais brasileiros, como cidades e sítios arqueológicos. A ideia de bem cultural, nesse contexto, vinculava-se à arte, como "habilidade com que o engenho humano se utiliza da ciência, das coisas e dos fatos" (ANDRADE apud BORGES, 1999, p. 3). Apesar do foco no "saber fazer", na prática, eram considerados bens culturais apenas as obras arquitetônicas, em especial o estilo barroco (BORGES, 1999). Em 1946, o SPHAN foi transformado em Diretoria do Patrimônio Histórico e Artístico Nacional (DPHAN) pelo Decreto no 8.534. Em 1970 o DPHAN foi transformado em IPHAN pelo Decreto no 66.967.

O Decreto-Lei n ${ }^{\circ} 25$, de 30 de novembro de 1937, define patrimônio histórico e artístico nacional como o "conjunto dos bens móveis e imóveis existentes no país e cuja conservação seja de interesse público, que por sua vinculação à fatos memoráveis da história do Brasil, quer por seu excepcional valor arqueológico ou etnográfico, bibliográfico ou artístico".

O bem, para ser tombado, deveria ser devidamente inscrito em um dos quatro Livros do Tombo ${ }^{1}$. Embora o Decreto-Lei não faça menção explícita à língua, é possível depreender a possibilidade de sua contemplação, de forma indireta,

\footnotetext{
1 Os quatro Livros do Tombo são: Livro do Tombo Arqueológico, Etnográfico e Paisagístico; Livro do Tombo Histórico; Livro do Tombo das Belas Artes; e Livro do Tombo das Artes Aplicadas. Disponível em <http://portal. iphan.gov.br/pagina/detalhes/608>. Acesso em: 11 fev. 2016.
} 
pelos Livros de Tombo de Belas-Artes, Histórico ou de Artes Aplicadas. Além dessa classificação posta pelos Livros, as oito categorias demarcadas por Mario de Andrade para os bens culturais eram: arte arqueológica, ameríndia, popular, histórica, erudita nacional, erudita estrangeira, aplicadas nacionais e aplicadas estrangeiras (GUEDES, 2001).

Apesar do amplo interesse pelo registro da diversidade cultural brasileira, contraditoriamente, o enfoque na diversidade das línguas parece não ter atraído um Estado nacionalista que estava fortemente preocupado com a construção imaginária de uma homogeneidade cultural. Esse interesse estatal pela "homogeneidade no campo cultural é visto como forma de assegurar a organização do regime, que busca invalidar as demais manifestações de cultura como prejudiciais ao interesse nacional" (VELLOSO, 1987, p. 24). Um exemplo da maneira como a construção de uma homogeneidade cultural deslizou para a defesa da homogeneidade linguística pode ser visto pelo discurso de Gustavo Capanema, Ministro da Educação, na Academia Brasileira de Letras em 1941:

Mas a verdade é que, nos seus elementos vocabulares e nos princípios de sua construção, permanece una a língua portuguesa. E nessa unidade ela deve persistir. Com essa unidade, poderá ela ser um meio de expressão de maior alcance e um mais rico elemento da cultura humana (PINTO, 1981, p. 467).

A construção e manutenção desse imaginário nacionalista homogêneo estava, então, fortemente vinculada às iniciativas de intelectuais em torno (i) da construção de discursos sobre identidade e cultura brasileiras; e (ii) da veiculação desse imaginário nacional por meio das mídias de massa que eram regidas pelo Estado. Dentre tais mídias, o rádio tornou-se veículo privilegiado da cultura com fins de construção de um sentimento nacionalista, sendo que a música popular desempenhou um papel importante no processo político (VELLOSO, 1987). Um exemplo de tentativa de homogeneização da forma de falar e cantar foi a realização do Primeiro Congresso de Língua Nacional Cantada, em 1937, que propunha e defendia a unificação das pronúncias:

No caso do Brasil, o estabelecimento normalizado da pronúncia cantada se impõe, da mesma forma e pelos mesmos motivos que a escolha da língua padrão [...] A desatenção a este problema por parte dos nosso cantores e professores de canto, de colaboração com a precariedade ortográfica da língua, estão levando o nosso canto erudito à maior barafunda vocal que se pode imaginar (PINTO, 1981, p. 375). 
Tem-se, portanto, que nesse contexto "a língua se constitui em patrimônio nacional, no sentido de que preserva a 'segurança e unidade' do país” (VELLOSO, 1987, p. 30). Assim, no Estado Novo, os intelectuais vinculados ao Ministério da Educação e ao Departamento de Imprensa e Propaganda (DIP) atuavam em duas frentes que se reforçavam mutuamente na construção e manutenção da memória nacional. A diversidade, então, operava no interior de uma política homogeneizante e assimilacionista.

A invenção, preservação e divulgação da cultura (seja erudita, seja popular) tornou-se foco estratégico dos interesses do Estado. É nesse período que produções literárias regionalistas - que enaltecem a brasilidade - passam a ser intensamente produzidas, bem como trabalhos acadêmicos de cunho historiográfico e culturalista, com os nomes de Guimarães Rosa e Gilberto Freyre. É também deste período que remontam produções linguísticas sobre dialetos brasileiros, como O dialeto caipira (1920), de Amadeu Amaral; o Linguajar carioca (1922), de Antenor Nascentes; a Lingua do Nordeste (1934), redigida por Mário Marroquim; o Vocabulário pernambucano (1937), por Pereira da Costa; os Estudos de dialetologia portuguesa: a linguagem de Goiás (1944), por José Aparecido Teixeira; A linguagem popular da Bahia (1951), por Édison Carneiro, entre outros (CASTILHO, 1972; SEVERO, 2013).

Tendo feito essa breve exposição sobre o surgimento das políticas de patrimonialização no Brasil com fins de construção de uma identidade cultural nacional homogênea, a seguir discorre-se sobre o lugar conferido à língua nessas políticas em diálogo com as políticas internacionais.

\subsection{A PATRIMONIALIZAC̣ÃO DA LÍNGUA NAS ESFERAS INTERNACIONAIS E NACIONAIS}

As políticas contemporâneas de patrimonialização dialogam fortemente com as iniciativas internacionais, dentre as quais a Convenção do Patrimônio Mundial da UNESCO (1972), a Recomendação sobre a Salvaguarda da Cultura Tradicional e Popular (1989) e a Convenção para a Salvaguarda do Patrimônio Cultural Imaterial (2003). Tais motivações da UNESCO foram fortemente embaladas pelas perdas culturais e históricas ocorridas em decorrência das duas Guerras Mundiais. A atuação da UNESCO ampliou o debate sobre preservação dos bens culturais para um nível global, a partir de iniciativas que buscavam mobilizar a proteção do patrimônio cultural por meio dos eixos da educação, ciência e cultura. A UNESCO, “órgão intelectual das Nações Unidas”, foi fundada em 1945 com o objeto de promover a paz mundial ao fomentar projetos 
interculturais e educacionais de caráter global. Exemplificando a sua atuação política, em 2013, a UNESCO definiu o período entre 2015 e 2024 como a "Década dos Afrodescendentes: reconhecimento, justiça e desenvolvimento", em busca do reconhecimento da contribuição africana na formação das sociedades e de luta contra o racismo.

Sobre o conceito de patrimônio, a Convenção de 1972 estabelece como patrimônio cultural os monumentos e os conjuntos, conforme descritos a seguir:

os monumentos: obras arquitetônicas, esculturas ou pinturas monumentais, objetos ou estruturas arqueológicas, inscrições, grutas e conjuntos de valor universal excepcional do ponto de vista da história, da arte ou da ciência; os conjuntos: grupos de construções isoladas ou reunidas, que, por sua arquitetura, unidade ou integração à paisagem, têm valor universal excepcional do ponto de vista da história, da arte ou da ciência (UNESCO, 1972).

Nota-se que o conceito de patrimônio cultural tende a valorizar as construções arquitetônicas. Exemplificando esse foco material, no Brasil, entre 1937 e 2014 foram tombados 1113 bens culturais materiais (IPHAN). O conceito de patrimônio cultural no Brasil - instituído pelo Decreto Lei n 25, de 30 de novembro de 1937 - foi expandido, passando a incluir os bens considerados de natureza imaterial, como as formas de expressão. Segundo a Constituição Brasileira (1988),

Art. 216. Constituem patrimônio cultural brasileiro os bens de natureza material e imaterial, tomados individualmente ou em conjunto, portadores de referência à identidade, à ação, à memória dos diferentes grupos formadores da sociedade brasileira, nos quais se incluem:

I - as formas de expressão;

II - os modos de criar, fazer e viver;

III - as criações científicas, artísticas e tecnológicas;

IV - as obras, objetos, documentos, edificações e demais espaços destinados às manifestações artístico-culturais;

V - os conjuntos urbanos e sítios de valor histórico, paisagístico, artístico, arqueológico, paleontológico, ecológico e científico.

Essa perspectiva dialoga com os conceitos jurídicos internacionais de patrimônio, que diferencia bens materiais e imateriais. A título de ilustração, a Convenção da UNESCO de 2003, em seu Art. $2^{\circ}$, define patrimônio cultural imaterial da seguinte maneira: 
Entende-se por “património cultural imaterial” as práticas, representações, expressões, conhecimentos e competências - bem como os instrumentos, objectos, artefactos e espaços culturais que lhes estão associados - que as comunidades, grupos e, eventualmente, indivíduos reconhecem como fazendo parte do seu património cultural. Este património cultural imaterial, transmitido de geração em geração, é constantemente recriado pelas comunidades e grupos em função do seu meio envolvente, da sua interacção com a natureza e da sua história, e confere-lhes um sentido de identidade e de continuidade, contribuindo assim para promover o respeito da diversidade cultural e a criatividade humana. [...]

O “património cultural imaterial” tal como é definido no parágrafo I supra, manifesta-se nomeadamente nos seguintes domínios: (a) tradições e expressões orais, incluindo a língua como vector do património cultural imaterial; (b) artes do espectáculo; (c) práticas sociais, rituais e actos festivos; (d) conhecimentos e usos relacionados com a natureza e o universo; (e) técnicas artesanais tradicionais (UNESCO, 2003; grifo nosso).

A diferenciação entre bens materiais e imateriais é complicada, uma vez que não há materialidade sem significados simbólicos e valorativos agregados, conferindo-lhe a possibilidade de ser patrimoniada. Diante dos discursos oficiais apresentados, percebe-se o percurso jurídico que vai possibilitar a consideração das línguas como bens culturais imateriais. Em diálogo com tais discursos, uma série de iniciativas globais, envolvendo Estados e sociedades civis (ONGs), têm respondido à demanda da UNESCO por meio de iniciativas de proteção das línguas consideradas ameaçadas de extinção. Exemplificando, 2008 foi elencado pela UNESCO como o ano internacional das línguas. Esse órgão também dispõe de um atlas linguístico digital que apresenta as línguas em situação de extinção no mundo ${ }^{2}$. O Atlas das Línguas em Perigo foi publicado pela UNESCO em 2000.

No Brasil, as políticas de proteção dos bens imateriais datam de 2000 (Decreto $\mathrm{n}^{\circ}$ 3.551), a partir da metodologia do registro. Contudo, as línguas foram apenas formalmente reconhecidas como patrimônio cultural imaterial pelo Decreto $\mathrm{n}^{\circ}$ 7.387, de 9 de dezembro de 2010, que instituiu o Inventário Nacional da Diversidade Linguística (INDL), entendido como "instrumento de identificação, documentação, reconhecimento e valorização das línguas portadoras de referência à identidade, à ação e à memória dos diferentes grupos formadores da sociedade brasileira". As línguas inscritas no Inventário são chamadas de "Referência Cultural Brasileira”. Em 2015, foram registradas as três primeiras línguas faladas

2 Disponível em: <http://www.unesco.org/languages-atlas/>. Acesso em: 11 fev. 2016. 
no Brasil por diferentes comunidades: a língua de imigração italiana Talian, fortemente presente na região sul do Brasil; a língua Asuriní do Trocará, do tronco linguístico Tupi, falada pelos Asurini do Trocará na Terra Indígena Trocará (PA); e a língua Guarani Mbya, uma das três variedades modernas da língua Guarani, também do tronco linguístico Tupi. Entre as categorias linguísticas consideradas passíveis de documentação no Brasil estão: línguas de imigração, indígenas, afrobrasileiras, de sinais, crioulas e variedades do português.

As formas de preservação dos bens culturais materiais e imateriais seguem metodologias diferentes. O tombamento, por exemplo, destina-se à preservação dos bens materiais móveis e imóveis, sendo registrados no Livro do Tombo; já o inventário - formalizado pela Constituição de 1988 - visa reconhecer e registrar bens culturais e ambientais, dedicando-se aos bens imateriais. A competência para o tombamento e o inventário é da União, Distrito Federal, estados e municípios. O tombamento e o inventário formalizam o papel do poder público na preservação e valorização dos bens culturais. A abordagem teórica e a metodologia utilizadas para inventariar as línguas foram divulgadas em dois Guias de Pesquisa e Documentação para o INDL (2014). O primeiro volume abarca a diversidade linguística existente no Brasil e as formas de inventário, pontuando questões teóricas; o volume dois centra-se no aspecto metodológico de levantamento das informações para documentação das línguas. Na próxima seção são discutidos os conceitos de língua das políticas de patrimonialização.

\subsection{PROBLEMATIZANDO A PATRIMONIALIZAC̣ÃO DAS LÍNGUAS}

A prática de patrimonialização das línguas pode ser problematizada em relação a, pelo menos, quatro aspectos, cujos efeitos políticos devem ser considerados: (i) reificação da língua; (ii) submissão das línguas a um discurso nacionalista; (iii) cristalização da relação entre língua, cultura, falantes e território; e (iv) consideração dos direitos linguísticos como concepção universal. Tais aspectos são abordados a seguir.

Sobre a reificação, a prática de patrimonialização se pauta em procedimentos metodológicos de construção de um objeto para fins de sua documentação e preservação. Em se tratando de política linguística, é preciso considerar que tais procedimentos não são neutros, mas inscrevem relações de poder que possibilitam a construção de discursos com efeitos de verdade (FOUCAULT, 1999). A prática de documentação linguística, por meio do registro e descrição de amostras - seguindo um critério "filogenético" em diálogo com a "autoidentificação" dos povos -, é 
um procedimento metodológico que constrói as línguas mediante procedimentos de recorte, classificação, agrupamento, designação, distribuição e exemplificação. Nesse contexto, a consideração da categoria de "autoidentificação" pelo INDL, longe de efetivamente dialogar com as motivações dos sujeitos, tende a produzir um simulacro de autenticidade, supostamente validando os argumentos linguísticos desses sujeitos a respeito da diversidade das línguas faladas no Brasil. Trata-se, com esses procedimentos metodológicos, de se produzir discursos que não são neutros, mas veiculam efeitos políticos, como a ideia ilusória de que esses discursos sobre as línguas espelham a complexidade das práticas linguísticas das pessoas e comunidades envolvidas. A reificação, pela transformação das práticas linguísticas em objetos, produz um novo discurso sobre língua. Nos alinhamos a uma abordagem discursiva em que a língua - tomada como enunciado - é tida como evento e, portanto, singular, contextualizada, irrepetível e única (BAKHTIN, 1993). Trata-se de uma concepção que problematiza a cristalização e ossificação das línguas em formatos estáticos e documentados.

A objetificação (das línguas, dos sujeitos, das experiências) caracteriza o "regime de verdade" (FOUCAULT, 1999) da nossa sociedade, em que as regras que definem o verdadeiro estão centradas no discurso científico e nas instituições que as validam. Com isso, assim como na Era Vargas, temos o conhecimento científico validando as políticas em torno das línguas faladas no Brasil. A reificação da língua, bem como de outros "bens" culturais, cria condições para a mercantilização desses objetos que, descolados das práticas locais, assumem um valor agregado no interior de um sistema capitalista: "A cultura transformase, assim, em produto a ser consumido e, nesse sentido, adquire um preço, correspondente à disposição do consumidor em pagar pela cultura, cristalizada em obras de arte e outros objetos dotados de valor cultural" (STEIGLEDER, 2010, p. 60). Com isso, a patrimonialização e mercantilização dos objetos andam lado a lado, pois ambos envolvem atribuição de valor (DIAS, 2012). Nesse processo, as línguas são descoladas de seus contextos de produção para circularem - e serem ressignificadas - em outros contextos, como o contexto estatal de bens culturais brasileiros.

Diante disso, não fica difícil deduzir a maneira como tais discursos funcionam a serviço da construção de uma ideia de nacionalismo, afinal, a diversidade linguística a ser documentada é definida no INDL como "Referência Cultural Brasileira", independente dos usos transfronteiriços e híbridos. A patrimonialização das línguas se inscreve, então, em uma prática mais ampla de construção de uma identidade e memória nacionais: "No Brasil, o debate sobre o patrimônio e os processos de patrimonialização tem estado, há décadas, inexoravelmente associado às questões da cultura e da identidade nacionais" (TRAJANO, 2012, p. 15). Com isso, argumenta-se que as práticas de levantamento 
da diversidade linguística existentes no Brasil devem ser vistas, necessariamente, em relação a uma vontade de governo - a uma política de Estado - que pretende, com esse saber, capilarizar e individualizar as formas de atuação, intervenção e controle (SEVERO, 2013). Nesse sentido, concordamos com a apreciação de Velloso (1987) sobre o papel da ciência (dos intelectuais) na política de Estado; embora sua avaliação estivesse centrada na Era Vargas, tal prática ainda ressoa nas políticas públicas contemporâneas:

Os intelectuais aparecem como porta-vozes dos anseios populares, porque seriam capazes de captar o "subconsciente coletivo" da nacionalidade. Neste subconsciente estariam contidas as verdadeiras reservas da brasilidade que o Estado Novo viria a recuperar, assegurando a continuidade da consciência nacional (VELLOSO, 1987, p. 18).

O mapeamento da diversidade linguística no Brasil pelo Estado é conduzido a partir de um interesse de manutenção da homogeneidade cultural, afinal, essa diversidade é agrupada sob o macrorótulo de Referência Brasileira. Além do escopo nacionalista, o reconhecimento da diversidade linguística - em consonância com outras políticas públicas de reconhecimento da diversidade cultural no Brasil - dialoga com as iniciativas internacionais centradas na interculturalidade funcional, em que o reconhecimento da diversidade visa a sua adequação à estrutura de poder existente, sem questionar as assimetrias políticas e históricas que caracterizam as sociedades (WALSH, 2009). Esse tipo de interculturalidade embala também as propostas internacionais e universalistas de reconhecimento da diversidade: a "Declaração da UNESCO defende a diversidade sem denunciar ou mudar o capitalismo globalizado" (WALSH, 2009, p. 6).

O INDL, ao definir as regras metodológicas de enquadramento e produção de discursos sobre as línguas faladas no Brasil sob o escopo de "Referência Brasileira", invisibiliza as práticas discursivas locais, uma vez que reduz a diversidade discursiva (diferentes visões de mundo) à diversidade linguística (diferentes sistemas linguísticos). Produz-se, com isso, a ideia de que a preservação das línguas significa preservação de culturas e identidades, conforme ilustra o excerto do Guia de Documentação para o INDL (BRASIL, 2014, v. 1, p. 23): “cada língua possui os meios específicos, historicamente construídos de se conceber, conhecer e agir sobre o mundo". Nota-se, no documento, uma sobreposição entre as ideias de língua e discurso, como se a preservação das línguas tornasse possível, automaticamente, a preservação de modos de compreender e agir no mundo. Essa relação biunívoca entre língua e cultura é oriunda das ideologias nacionalistas europeias que mobilizaram a construção do imaginário social de uma língua, um Estado e uma cultura. É como se afirmássemos que a cosmovisão indígena 
ou a cultura do imigrante estivessem essencialmente atreladas às suas línguas. Contestando essa visão, concordamos com o argumento de Maher (1998, p. 117) a respeito da construção da identidade indígena: "é, assim, o discurso, isto é, a linguagem em uso, e não qualquer materialidade linguística específica [...], quem cria e faz circular o sentido de "ser índio"”.

A ideia romântica, presente no INDL, de que a perda das línguas significaria a perda de conhecimentos e saberes, justificaria a inscrição (política) do letramento nas sociedades orais como forma de memória, como ocorreu com o latim, o grego ou o sânscrito (EDWARDS, 2009). Além disso, a patrimonialização das línguas pela sua documentação não garante sua existência efetiva, podendo, apenas, engrossar a retórica estatal nacionalista e "multicultural". Em outras palavras, a documentação não garante que a transmissão linguística entre gerações continue. Assim, a situação de enfraquecimento ou desaparecimento das línguas está fortemente vinculada às relações de poder e condições sociais e históricas de seus falantes. Uma política linguística que desconsidere esses aspectos funciona de forma retórica e, muitas vezes, opera ocultando as reais motivações da desigualdade e discriminação linguísticas.

Além dessa correlação direta que se estabelece entre língua e cultura, o documento também territorializa as línguas faladas no Brasil. O mapeamento linguístico implica, também, o mapeamento de seus falantes: "o inventário deverá dar conta, sempre que possível, do território da comunidade linguística a partir da identificação de um conjunto de LOCALIDADES DE OCORRÊNCIA DA LÍNGUA" (BRASIL, 2014, v. 1, p. 42; grifo do autor). Este é um discurso bastante delicado, se pensarmos nas políticas de Estado envolvendo as demarcações de terra de comunidades indígenas e quilombolas, por exemplo. Não por acaso, o INDL não se restringe à tutela dos Ministérios da Cultura (IPHAN) e da Educação, mas é gerido, também, pelo Ministério da Justiça e pelo Ministério do Planejamento, Orçamento e Gestão. Ou seja, as línguas se tornam uma questão econômica e de justiça, pois envolve pessoas que foram historicamente excluídas e desalojadas. Vale lembrar que o Ministério da Justiça é corresponsável pelo processo de demarcação de terras no Brasil, em diálogo com o Instituto Nacional de Colonização e Reforma Agrária (INCRA) e a Fundação Nacional do Índio (FUNAI).

Juntamente com os aspectos discutidos anteriormente, o documento também veicula um discurso de proficiência atrelado à categorização dos sujeitos-falantes. Assim, ocorre um agrupamento de pessoas (BRUBAKER, 2002) a partir de critérios linguísticos, em um contínuo de proficiência, como indicam as seguintes categorias: falantes fluentes, falantes parciais, não falantes, falantes de referência e falantes potenciais. Os níveis de proficiência definiriam essas categorias identitárias. Exemplificando, os falantes parciais seriam aqueles que "têm uma 
compreensão razoável da língua [...], que 'entendem bem, mas falam pouco sua língua' ou 'entendem um pouco, mas não falam a sua língua'” (BRASIL, 2014, v. 1, p. 38). Ressaltamos que o conceito de proficiência é bastante complexo e deve ser problematizado, pois envolve a capacidade de produção e compreensão de sentidos em contextos culturais diferentes. Para ilustrar, em algumas comunidades indígenas, a proficiência está vinculada ao domínio de um vasto repertório de cantos (MAHER, 2010) e não, necessariamente, à habilidade comunicativa do dia-a-dia.

O Guia para o INDL reafirma o seu compromisso com a política internacional de direitos humanos e direitos linguísticos. Trata-se de um discurso de cunho universalista que, curiosamente, opera paralelamente aos discursos locais, de natureza nacionalista. A adoção de um modelo universalista de direitos linguísticos deve ser relativizada diante de contextos linguisticamente complexos em que: os limites entre as línguas são imprecisos; as identidades e práticas comunicativas são dinâmicas; existe uma complementariedade entre as práticas comunicativas de diferentes grupos étnicos; existem amálgamas estilísticos e linguístico-discursos variáveis e dinâmicos, especialmente em contextos orais, que não são facilmente apreendidos por olhares externos (MAKONI, 2011). Diante disso, a atribuição de direitos - a uma prática que resiste à objetificação - torna-se complicada.

Ademais, a categorização das línguas desliza para categorizações étnicas, produzindo agrupamentos linguísticos rígidos que têm efeitos políticos sobre as pessoas e a maneira como elas se percebem. Afinal, nada impede que as pessoas falem as mesmas línguas e pertençam a grupos étnicos diferentes. Além isso, o paradigma dos direitos linguísticos "busca introduzir justiça social ao aplicar uma 'ficção' e enfatizar diferenças entre etnicidades, enquanto diferenças no interior das etnicidades são negligenciadas" ${ }^{3}$ (MAKONI, 2011, p. 13). As políticas de patrimonialização, ao construir discursos ficcionais sobre as línguas com fins de sua proteção e conservação, produzem efeitos políticos sobre as pessoas e as comunidades. É preciso considerar que as línguas não existem independente dos falantes e de suas histórias e experiências. Além disso, muito embora o INDL considere o critério de autoidentificação para definir as línguas, essas passam a ser cristalizadas pela prática da documentação e pela sua interpretação à luz de uma abordagem filogenética. Nesse contexto da autoidentificação, deve-se considerar seriamente que o que emerge nas pesquisas de documentação é uma "discrepância entre as declarações dos indivíduos e o conhecimento atual dos linguistas” (BRASIL, 2014, v. 1, p. 20, nota 5).

\footnotetext{
3 “The LR paradigm, therefore, seeks to introduce social justice by applying a 'fiction' and by stressing differences between ethnicities while social differences within ethnicities are overlooked."
} 


\subsection{CONSIDERAÇÕES FINAIS}

Este capítulo teve como objetivo problematizar o conceito de língua das políticas brasileiras de patrimonialização. Para tanto, foi feita uma apresentação geral do percurso histórico envolvendo as iniciativas estatais de preservação dos bens culturais, conferindo atenção especial ao papel dos intelectuais no processo de construção de uma identidade nacional brasileira. Em seguida, foram apresentados os conceitos de patrimônio material e imaterial, de tombamento e de inventário, com fins de contextualizar as línguas nessa chave conceitual. A terceira seção dedicou-se a problematizar o conceito de língua nessas políticas públicas, tendo em vista a objetificação das práticas linguísticas pela patrimonialização, desassociando língua e sujeitos. $\mathrm{O}$ interesse pelas pessoas se justifica na medida em que "no final do dia, são as pessoas comuns que terão que conviver com as decisões e processos e que, finalmente, terão que julgá-los" ${ }^{4}$ (EDWARDS, 2007, p. 264).

Em políticas linguísticas, considera-se essencial que o ponto de vista dos sujeitos envolvidos seja seriamente considerado. Deve-se evitar que critérios importantes como a autoidentificação sejam usados a favor da criação de um "simulacro de autenticidade", não dialogando, de fato, com os sujeitos envolvidos. Dado que as práticas de patrimonialização das línguas reverberam os discursos dos direitos humanos e direitos linguísticos, de inspiração universalista, considera-se fundamental que as pessoas - cujas línguas são alvo das políticas de preservação - sejam indagadas a respeito dos significados locais que elas atribuem a direitos linguísticos e direitos humanos, inclusive à ideia de "humano" que, muitas vezes, favorece uns em detrimento de outros.

\subsection{REFERÊNCIAS}

ABREU, R. A emergência do patrimônio genético e a nova configuração do campo do patrimônio. In: ABREU, R.; CHAGAS, M. (Orgs.). Memória e patrimônio: ensaios contemporâneos. 2. ed. Rio de Janeiro: Lamparina, 2009. p. 25-33.

BAKHTIN, M. Para uma filosofia do ato (1919-1921). Tradução inédita, sem revisão, destinada a uso didático, de Carlos Alberto Faraco e Cristóvão Tezza,

\footnotetext{
4 "At the end of the day, it is ordinary people who will live with the decisions and processes, and who will ultimately judge them."
} 
do texto da edição americana Toward a philosophy of the act. Austin: University of Texas Press, 1993.

BORGES, C. Patrimônio e memória social: a formação da política de preservação de bens históricos no Brasil e a construção do imaginário coletivo. Locus: Revista de História, Juiz de Fora, v. 5, n. 2, p. 1-13, 1999.

BRASIL. Instituto do Patrimônio Histórico e Artístico Nacional. Guia de pesquisa e documentação para o INLD: patrimônio cultural e diversidade linguística. Brasília, DF, 2014.

BRUBAKER, R. Ethnicity without groups. Archives of European Sociology, Cambridge, n. XLIII, v. 2, p. 163-189, 2002.

CASTILHO, A. Rumos da dialetologia portuguesa. Alfa: Revista de Linguística, São Paulo, v. 18/19, p. 115-153, 1972.

DIAS, J. B. Registros fonográficos da música cabo-verdiana: mercadoria e Patrimônio. In: SANSONE, L. (Org.). Memórias da África: patrimônios, museus e políticas das identidades. Salvador: Aba Publicações, 2012. p. 41-66.

EDWARDS, J. Back from the brink: The revival of endangered languages. In: HELLINGER, M.; PAUWELS, A. Handbook of language and coomunication: diversity and change. New York: Mouton de Gruyter, 2007. p. 241-270.

. Language and identity: an introduction. New York: Cambridge University Press, 2009.

FAUSTO, B. História concisa do Brasil. São Paulo: Edusp, 2002.

FOUCAULT, M. Verdade e Poder. In: . Microfísica do poder. 14. ed. Rio de Janeiro: Graal, 1999. p. 1-14.

GUEDES, T. O lado doutor e o gavião de penacho: Movimento Modernista e Patrimônio Cultural no Brasil. Serviço do Patrimônio Histórico e Artístico Nacional. São Paulo: AnnaBlume, 2001.

IPHAN - INSTITUTO DO PATRIMÔNIO HISTÓRICO E ARTÍSTICO NACIONAL. Guia de Pesquisa e Documentação para o INDL, v. 1. Brasília, DF, IPHAN, 2014. IPHAN, 2014.

. Guia de Pesquisa e Documentação para o INDL, v. 2. Brasília, DF,

LABOV, W. Sociolinguistic patterns. Philadelphia: Philadelphia University Press, 1972.

MAHER, T. M. Sendo índio em português. In: SIGNORINI, I. (Org.). Língua(gem) e Identidade: elementos para uma discussão no campo aplicado. Campinas: Mercado das Letras, 1998, p. 115-138.

- Políticas linguísticas e políticas de identidade: currículo e representações de professores indígenas na Amazônia Ocidental brasileira. Currículo sem Fronteiras, [s.1,], v. 10, n. 1, p. 33-48, 2010. 
MAKONI, S. Language and human rights discourses in Africa: lessons from the African experience. Journal of Multicultural Discourses, v. 07, n. 01, p. 1-20, 2012.

PINTO, E. P. O Português do Brasil: textos críticos e teóricos. Fontes para a teoria e a história. Rio de Janeiro: Livros Técnicos e Científicos; São Paulo: Editora da Universidade de São Paulo, 1981.

VELLOSO, M. P. Os intelectuais e a política cultural do Estado Novo. Rio de Janeiro: Centro de Pesquisa e Documentação de História Contemporânea do Brasil, 1987.

SCHWARCZ, L. M. O espetáculo das raças: cientistas, instituições e pensamento racial no Brasil: 1870-1930. São Paulo: Companhia das Letras, 2008.

SEVERO, C. G. A diversidade linguística como questão de governo. Calidoscópio, v. 1, p. 107-115, 2013.

STEIGLEDER, A. M. Critérios de valoração econômica dos danos a bens culturais materiais. Revista Magister de Direito Ambiental e Urbanístico, v. 27, 2010, p. 56-82.

TRAJANO, W. Patrimonialização dos artefatos culturais e redução dos sentidos. In: SANSONE, L. (Org.). Memórias da África: patrimônios, museus e políticas das identidades. Salvador: Aba Publicações, 2012, p. 11-40.

UNESCO. Convenção para a Proteção do Patrimônio Mundial, Cultural e Natural, 1972.

, Salvaguarda do Patrimônio Cultural Imaterial, 2003.

WALSH, C. Interculturalidade e (des)colonialidade: perspectivas críticas e políticas. Anais do XII Congresso ARIC, Florianópolis, 2009. 
